\title{
Corrigendum to "System Analysis of ROS-Related Genes in the Prognosis, Immune Infiltration, and Drug Sensitivity in Hepatocellular Carcinoma"
}

\author{
Jun Hui Xu $\left(\mathbb{D},{ }^{1,2,3}\right.$ Yong Jun Guan $\mathbb{D}^{1},{ }^{1}$ Zhen Dong Qiu $\left(\mathbb{D},{ }^{1}\right.$ Xin Zhang ${ }^{\mathbb{D}},{ }^{1}$ Liu Liu Zi ${ }^{\mathbb{D}},{ }^{1}$

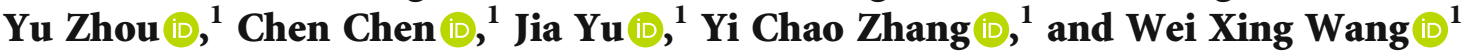 \\ ${ }^{1}$ Department of Hepatobiliary Surgery, Renmin Hospital of Wuhan University, Wuhan, China \\ ${ }^{2}$ Central Laboratory, Renmin Hospital of Wuhan University, Wuhan, China \\ ${ }^{3}$ Hubei Key Laboratory of Digestive System Disease, Wuhan, China
}

Correspondence should be addressed to Yi Chao Zhang; 409849352@qq.com and Wei Xing Wang; sate.llite@163.com

Received 22 January 2022; Accepted 22 January 2022; Published 21 February 2022

Copyright (C) 2022 Jun Hui Xu et al. This is an open access article distributed under the Creative Commons Attribution License, which permits unrestricted use, distribution, and reproduction in any medium, provided the original work is properly cited.

In the article titled "System Analysis of ROS-Related Genes in the Prognosis, Immune Infiltration, and Drug Sensitivity in Hepatocellular Carcinoma" [1], the authors identified an error in the abstract that was introduced during the preparation of the manuscript. The last sentence should be corrected as follows:

"Furthermore, we demonstrated that STK25 knockdown could increase the proliferation, migration, and invasion capacity of HCC cells." should be corrected to "Furthermore, we demonstrated that STK25 knockdown could decrease the proliferation, migration, and invasion capacity of HCC cells."

\section{References}

[1] J. H. Xu, Y. J. Guan, Z. D. Qiu et al., "System analysis of ROSrelated genes in the prognosis, immune infiltration, and drug sensitivity in hepatocellular carcinoma," Oxidative Medicine and Cellular Longevity, vol. 2021, Article ID 6485871, 30 pages, 2021. 